\title{
Image Case: Ascaris Worm Extraction During Upper Gastrointestinal Endoscopy
}

\author{
Mohamed H Emara, Ibrahim M Ibrahim \\ ${ }^{I}$ Tropical Medicine Department , Faculty of Medicine, Zagazig University, Egypt
}

Corresponding Author Mohamed H. Emara

Nematode infection including Ascariais is a worldwide infection [1,2]. Nematode email:emara_20007@yaho infection in particular ancylostomiasis and o.com

mobile: +01002724482

Received :11/1/2012 Accepted after revision $: 4 / 2 / 2012$ ascariasis have long been prevalent in Egypt and trials to trace this infection goes back to Lord Kitehenere in 1913 [3]. Although the decline in the incidence of this form of infection in Egypt, due to application of good hygienic techniques, mass and effective treatment ......etc, we reported a 55 years old male patient with chronic hepatitis $\mathrm{C}$ virus infection, non- responder to pegylated interferon therapy complained from persistent epigastric pain and was non-responder to multiple courses of proton pump inhibitors. We decided to examine this patient by upper gastrointestinal endoscopy, where this long white worm was seen in the duodenum ; extraction by biopsy forceps was done.

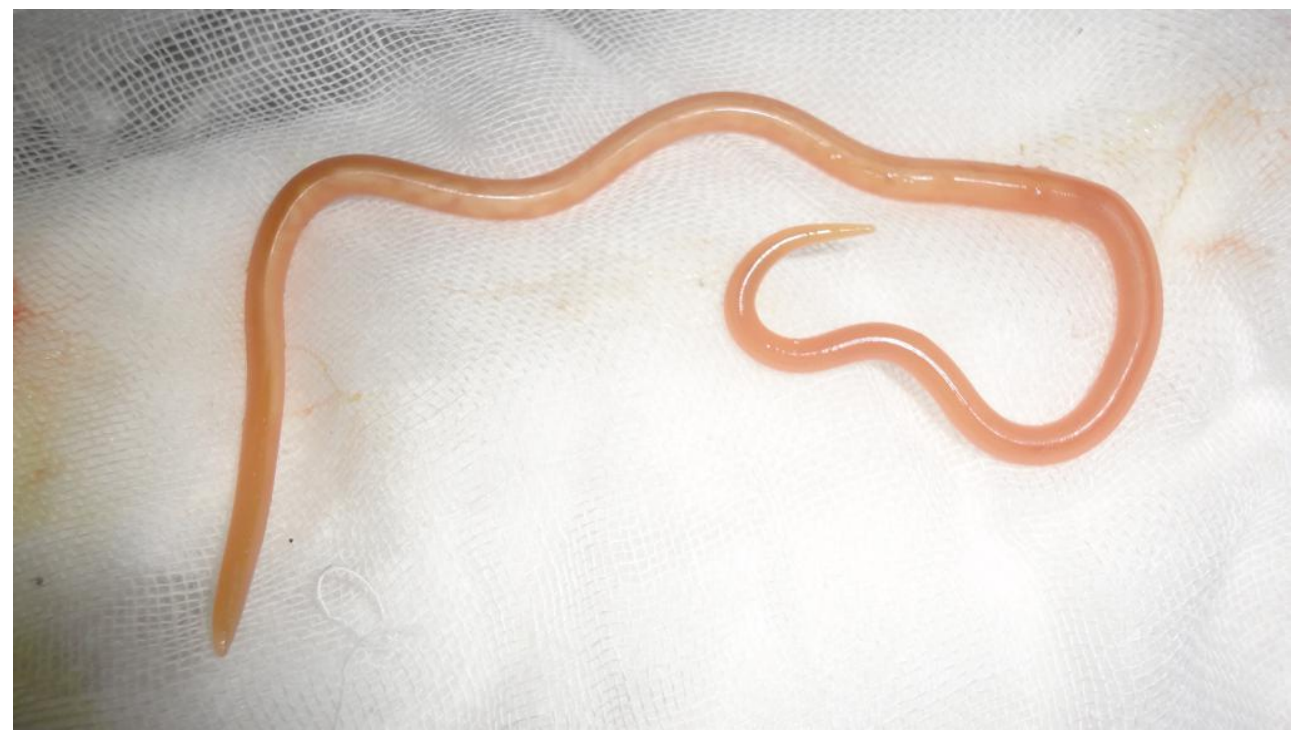

\section{REFERENCES}

1. Berger SA, Marr JS. Human Parasitic Diseases Sourcebook. Jones and Bartlett Publishers: Sudbury, Massachusetts, 2006.

2. Chan MS. The global burden of intestinal nematode infections - fifty years on. Parasitol. Today 1997, 13: 438-443.
3. Augustine DI, Helmy M, Nazmi M. Ancylostomiasis and ascariasis in Egypt. Am. J. Epidemiol. 1930, 11,1: 136-148. 